\title{
Evolution of Homo sapiens in Asia: an alternative implication of the "Out-of-Africa" model based on mitochondrial DNA data
}

\author{
Hiroto Naora
}

Research School of Biology, The Australian National University, Canberra, Australia; hiroto.naora@anu.edu.au

Received 25 September 2009; revised 9 November 2009; accepted 14 January 2010.

\begin{abstract}
Cann et al. [1] have claimed on the basis of mitochondrial DNA (mtDNA) data that our direct ancestral Homo sapiens evolved in the African continent and spread to other continents, followed by the total replacement of the indigenous population. Their "Out-of-Africa" model is based on the assumption that mtDNA inheritance is simply maternal. Recent findings suggest the possibility that in between-population, e.g. African and Asian, mating, the African paternal mtDNA was transferred to the egg cell of an Asian together with Y-chromosomal DNA in the human past. Considering that Y-chromosomal DNA and mtDNA sequences of African origin coexist together with Asian X-chromosomal and autosomal DNA sequences in a current Asian, the observations by Cann et al. suggest the full/near full replacement of $m t D N A$ in the human past, but do not necessarily imply the total replacement of indigenous populations with African migrants.
\end{abstract}

Keywords: Out-of-Africa Model; Origin of Asian; Paternal mtDNA Inheritance; mtDNA Transmission/ Recombination

\section{INTRODUCTION}

Evidence has accumulated that the Homo lineage originally appeared in Africa, followed by its successful global expansion. The view of "Out-of-Africa" that our direct ancestral $H$. sapiens evolved in the African continent and spread to other continents, has been popularly received among researchers [1-8]. On the other hand, there have been significant fossil records in non-African continents, supporting the "regional continuity" model [9]. This model claims that our direct ancestral H. sapiens evolved locally in the widespread regions of major con- tinents, e.g. Africa, Europe and Asia [10-12]. In fact, morphological continuity in East Asian traits from East Asian Homo erectus during the middle-late Pleistocene transition can be seen in these fossil records [12-14]. However, most of these records have neither definitely refuted nor supported one of the models for or against the origin of H. sapiens, particularly in Asia. Furthermore, most genetic evidence, such as simulated dendrograms, genetic diversity and ancient DNA sequences can argue for either model of human origin [15].

In 1987, a crucial observation was made by Cann et al., who examined the human mitochondrial DNA (mt DNA) diversity of globally dispersed populations. They concluded that modern humans simply spread to other continents, e.g. East Asia, from Eastern Africa around 200,000 years to 50,000 years ( $200 \mathrm{KY}$ to $50 \mathrm{KY}$ ) ago, followed by the total replacement of pre-inhabited indigenous populations $[1,2]$. The "Out-of-Africa" model, reconstructed with mtDNA data, is primarily based on a few assumptions. One of the key assumptions is that animal mtDNA does not undergo homologous recombination. This is because of past failure to observe the clear cases of mtDNA recombination in natural populations. However, recent findings have raised a new insight into mtDNA inheritance and the behaviours of mtDNA in a fertilised egg [16,17]. In this study, an attempt was made to integrate the interdisciplinary information obtained in the research fields, not only anthropology and mitochondrial genetics but also other areas, such as developmental biology, ecology and social sciences. A metaanalysis of these findings has raised the need of careful scrutiny in the interpretation of Cann et al. [1,2].

\section{CRITICAL VIEW OF MITOCHONDRIAL DNA INHERITANCE: STRICTLY MATERNAL?}

Two sibling bat species, European Myotis myotis and newly migrated M. blythii to Europe from Asia, share 
multiple identical or very similar haplotype in mitochondrial genomes when they occur in sympasy. However, they show a strikingly different pattern of nuclear DNA diversity. On the other hand, allopatric M. blythii in Asia possesses mtDNA divergent from those of two species in Europe, postulating that the mtDNA of European $M$. blythii has been replaced with that of M. myotis [18]. Similar mtDNA (full/near-full/partial) replacement has been observed in a wide variety of other species in an animal kingdom, for example, nematodes [19], molluscs [20], insects [21], fishes [22] and mammals other than bats, such as vole [23]. As opposed to the popular belief, all of these observations suggest that paternal mtDNA inheritance occurs widely in the animal kingdom. In fact, paternal mtDNA inheritance has been observed even in humans $[24,25]$. At present, no specific information has been reported, which strongly favours the notion that these human cases were really exceptional and that human mtDNA replacement, similar to the cases of Myotis, has never taken place in evolution when two "sibling" human populations met and lived in sympasy. Furthermore, evidence has shown that the segregation and transmission of mtDNA sequences [26-28] play a crucial role in the inheritance of human mitochondrial diseases [16].

Molecular and cellular events at an early stage of fertilisation would also provide us with more information which we can not ignore the view of paternal mtDNA inheritance in human. During the process of fertilisation in mammals, up to 100 sperm mitochondria actually enter an egg cell, together with the sperm head [17,29, 30]. However, these paternal mtDNAs are soon destroyed by a selective elimination mechanism, including ubiquitination of paternal mitochondria [30]. However, the elimination mechanism in the fertilised egg cell is not always highly stringent and fails to destroy all of the inserted paternal mitochondria, causing paternal leakage [30]. Such leakage was observed in mice progeny at a frequency of around one in 10,000 [31]. An interesting observation was that when "non-self" paternal mitochondria - in terms of the population/subspecies/species, to which the mating partner belongs - are inserted into the egg cell, such as in the mating between cow and gaur, these mitochondria are not eliminated and remain active in the fertilised egg cell [30]. In the mating between two inbred mouse strains, Mus musculus and M. spretus, a similar escape of paternal mitochondria through the elimination mechanism was observed as well [32]. These leakages would lead to a heteroplasmic offspring and thereby enhance the opportunity of transmission or recombination. It has been shown that human mitochondrial particles are fully equipped with the toolkits required for recombination [33-35]. Furthermore, each mitochondrial organelle holds the mechanisms, leading from heteroplasmy to the transmission of mtDNA [16, 28]. The detailed molecular mechanisms for paternal mtDNA inheritance and replacement might differ from one case to the other [36] and, at present, remain to be examined in each case.

\section{THE POSSIBLE FULL/NEAR-FULL REPLACEMENT OF MTDNA SEQUENCES IN THE HUMAN PAST}

It is highly likely that the anatomically modern humans that originated in Africa were different from those who inhabited in allopasy in the Asian continent for a long evolutionary period [37]. Furthermore, different populations have differing variation in biological responses [38]. Therefore, African migrants and indigenous inhabitants in Asia were likely to show different recognition responses to the partner's paternal mitochondria in their "between-population" mating although they were sibling and hybridisable. Thus, the ubiquitin-tagged paternal mitochondria, which were inserted in the egg cell, would not be subject to stringent mitochondrial elimination and could survive in the fertilised egg cell, as seen in the case of cow and gaur pairing [30]. There would be a huge difference in recognition response between Palaeolithic African migrant and inhabited Asians, who had never exposed to Africans and thus much more paternal (African) mtDNA molecules might had remained active without any damages in Asian egg cells in their "between-population" mating. Since current human populations have already mixed each other in some degree, I believe that much more African paternal mtDNA molecules had survived in Palaeolithic Asian egg cells than those we suspect in current "between-population" mating.

Most, if not all, of advocates for the "Out-of-Africa" model based on mtDNA data often argue against the alternative model of human origine on the following basis: The alternative model has not based on the conclusive evidence showing the recombination/paternal transmission of mtDNA in the human past. However, we should realise that the "Out-of-Africa" model has been standing on the shaky - recently much more shakyground without any explicit and conclusive evidence, showing that any recombination/paternal transmission of mtDNA had not taken place in the human past. In fact, Wilson [39] has mentioned that many puzzles have remained between Y-chromosome and mtDNA data in the conservative interpretation of the complex data in human migration. In the present paper, I have already mentioned the new findings, which include the paternal mtDNA behaviours in the fertilised eggs and the recombination/paternal transmission of mtDNA in the wide 
range of animal kingdom. In fact, taking all of these new findings into consideration, it is much more difficult to prepare a reasonable explanation for the notion that a series of the events, leading to the replacement of maternal mtDNA with the paternal DNA, had never taken place in the human past. As already mentioned, the transmission or recombination of mtDNA in the animal kingdom has occurred more frequently and more widely than we have previously suspected. Therefore, the limited human cases that have been currently reported so far on the replacement of mtDNA should not be claimed against the argument for the possible replacement events in the human past.

Cann et al. [1] have shown that the mtDNA itself of current humans in the Asian continent is really of African origin. However, their claim that indigenous inhabitants in Asia became completely extinct and were totally replaced with African migrants is confusing. As will be discussed in the next section, the present meta-analysis shows that ironically, their result together with chromosomal DNA sequences can nicely account for the possible paternal mtDNA inheritance in the human past. Thus, this novel view does not necessarily imply the extinction of Asian indigenous inhabitants, followed by the total replacement of the human population in Asia.

\section{DISCUSSION AND CONCLUSION}

The estimated ages of the most recent common ancestor (MRCA) of Y-chromosomal DNA sequences, such as several sites on SRY and YAP regions, were around 150 KY ago [40]. Current non-African men carry the M168 mutation, which arose in Africa during the period of 89 $\mathrm{KY}$ to $35 \mathrm{KY}$ ago [41-43]. All of these sequences on $\mathrm{Y}$-chromosome were much younger than those $(1,860$ $\mathrm{KY}$ to $535 \mathrm{KY}$ ago) of X-chromosomal DNA sequences, e.g. gene coded for pyruvate dehydrogenase E1 $\alpha$ [44] and non-coding sequences $\mathrm{Xq}$ [45], and autosomal DNA sequences, e.g. gene coded for $\beta$-globin [46] and non-coding sequences on chromosome 22 [47]. It should be noted that the MRCA ages of Y-chromosomal DNA sequences roughly correspond to the time (200 KY-100 KY ago) of human migration to Asia and thus that the $Y$-chromosomal and mtDNA sequences were likely to arise in the ancestor who lived in Africa around $<200$ KY ago [2]. On the other hand, the DNA sequences on $\mathrm{X}$-chromosome and autosomes could be traced back to the era of $H$. erectus in Asia [10,48-50]. Therefore, these results clearly suggest that the current Asians would be the offspring of the hybrids resulting from the mating between migrated Africans and indigenous Asian inhabitants. However, it appears likely that African migrants brought only African Y-chromosomal and mt D-
NA sequences to Asia [51] and most of Asian X-chromosomal and autosomal DNA sequences remained in the hybrid offspring. The most plausible scenario of the event in Palaeolithic Asia would be as follows: In the "between-population" mating, African Y-chromosomal DNA entered an Asian egg cell, accompanying with his mtDNA. The newly inserted paternal mtDNA remained intact without any significant damage/elimination in the fertilised egg cell and then formed heteroplasmy in the hybrid. After a series of transmission or recombination processes, the maternal mtDNA of Asian origin was fully/near-fully replaced with the paternal (African) mtDNA. Considering the possibility that the dilution-out and/or selective sweep of African X-chromosomal and autosomal DNA sequences might have occurred for evolutionary advantage, the X-chromosomal and autosomal DNA sequences of Asian origin would tend to be preserved more often and finally would be maintained as a major component in the East Asian population [52]. Therefore, the male offspring, including a current Asian male, would not necessarily be the direct descendant of a replaced African, but would be the hybrid offspring possessing the mitochondrial and Y-chromosomal DNA sequences of African origin, together with Asian X-chromosomal and autosomal DNA sequences. The sequence data, if possible, of chromosomal DNA and mtDNA of Palaeolithic Asian remains and the comparison with those of current humans in different populations should give a brighter view on this issue. The view raised in this paper would open a new research field of biological interactions, particularly in "between-population" reproduction in the human past.

\section{ACKNOWLEDGEMENTS}

I thank Prof. D. Clark-Walker (The Australian National University) and Dr. A. Thorne (The Australian National University) for their critical reading of the manuscript, and valuable suggestions and conversations.

\section{REFERENCES}

[1] Cann, R.L., Stoneking, M. and Wilson, A.C. (1987) Mitochondrial DNA and human evolution. Nature, 325 (6099), 31-36.

[2] Cann, R. (2001) Genetic clues to dispersal in human populations: Retracing the past from the present. Science, 291(5509), 1742-1748.

[3] Ingman, M., Kaessmann, H., Pääbo, S., et al. (2000) Mitochondrial genome variation and the origin of modern humans. Nature, 408(6813), 708-713.

[4] Stringer, C. (2003) Human evolution: Out of Ethiopia. Nature, 423(6941), 692-695.

[5] White, T., Asfaw, B., de Gusta, D., et al. (2003) Pleistocene Homo sapiens from Middle Awash, Ethiopia. $\mathrm{Na}$ ture, 423(6941), 742-747. 
[6] McDougall, I., Brown, F. and Fleagll, J. (2005) Stratigraphic placement and age of modern humans from Kish, Ethiopia. Nature, 433(7027), 733-736.

[7] Manica, A., Amos, W., Balloux, F. et al. (2007) The effect of ancient population bottle necks on human phenotypic variation. Nature, 448(7151), 346-349.

[8] Gibbons, A. (2009) Africans' deep genetic roots reveal their evolutionary story. Science, 324(5927), 575.

[9] Thorne, A.G. and Wolpoff, M.H. (1991) Conflict over modern human origins. Search, 22, 175-177.

[10] Brooks, A.S. and Wood, B. (1990) The Chinese side of the story. Nature, 344(6264), 288-289.

[11] Frayer, D.W., Wolpoff, M.H., Thorne, A.G., et al. (1993) Theories of modern human origins: The palaeontological test. American Anthropologist, 95(1), 73-96.

[12] Shang, H., Tong, H., Zhang, S., et al. (2007) An early modern human from Tianyuan Cave, Zhoukoudian, China. Proceedings of the National Academy of Sciences, USA, 104(16), 6573-6578.

[13] Etler, D.A. (1994) The Chinese Hominidae: New findings, new interpretations. The $\mathrm{Ph}$. $\mathrm{D}$. thesis, submitted to the Graduate Division of the University of California at Berkeley.

[14] Wu, X. and Poirier, F.E. (1995) Human evolution in China: A metric description of the fossils and a review of the sites. Oxford University Press, New York.

[15] Eller, E., Hawks, J. and Relethford, J.H. (2004) Local extinction and recolonization, species effective population size and modern human origins. Human Biology, 76(5), 689-709.

[16] Howell, N., Chinnery, P.F., Ghosh, S.S., et al. (2000) Transmission of the human mitochondrial genome. $\mathrm{Hu}$ man Reproduction, 15(Suppl 2), 235-245.

[17] Rokas, A., Ladoukakis, E. and Zouros, E. (2003) Animal mitochondrial DNA recombination revisited. Trends in Ecology and Evolution, 18(8), 411-417.

[18] Berthier, P., Excoffier, L. and Ruedi, M. (2006) Reccurrent replacement of mtDNA and cryptic hybridization between two sibling species Myotis myotis and Myotis blythii. Proceedings of the Royal Society B, 273(1605), 3101-3109.

[19] Lunt, D.H. and Hyman, B.C. (1997) Animal mitochondrial DNA recombination. Nature, 387(6630), 247.

[20] Ladoukakis, E.D. and Zouros, E. (2001) Direct evidence for homologous recombination in mussel (Mytilus galloprovincialis) mitochondrial DNA. Molecular Biology and Evolution, 18(7), 1168-1175.

[21] Powell, J.R. (1983) Interspecific cytoplasmic gene flow in the absence of nuclear gene flow: Evidence from Drosophila. Proceedings of the National Academy of Sciences, USA, 80(2), 492-495.

[22] Bernatchez, L., Glemet, H., Wilson, C.C., et al. (1995) Introgression and fixation of arctic char (Salvelinus alpinus) mitochondrial genome in an allopatric population of brook trout (Salvelinus fontinalis). Canadian Journal of Fishery and Aquatic Sciences, 52(1), 179-185.

[23] Telgelström, H. (1987) Transfer of mitochondrial DNA from northern red-backed vole (Clethrionomys rutilus) to bank vole (C. glareolus). Journal of Molecular Evolution, 24(3), 218-227.

[24] Hagelberg, E., Goldman, N., Lió, P., et al. (1999) Evidence for mitochondrial DNA recombination in a human population of island Melanesia. Proceedings of the Royal Society B, London, 266(1418), 485-492.

[25] Schwartz, M. and Visssing, J. (2002) Paternal inheritance of mitochondrial DNA. New England Journal of Medicine, 347(8), 576-580.

[26] Birky, Jr, C.W., Acton, A.R., Dietrich, R., et al. (1982) Mitochondrial transmission genetics: replication, recombination and segregation of mitochondrial DNA and its inheritance in crosses. In: Stonimski, P., Borst, P. and Attardi, G., Eds., Mitochondrial genes. Cold Spring Harbor Laboratory, Cold Spring Harbor, 333-348.

[27] Hauswirth, W.W. and Laipis, P.J. (1982) Rapid variation in mammalian mitochondrial genotypes: Implications for the mechanism of maternal inheritance. In: Stonimski, P., Borst, P. and Attardi, G., Eds., Mitochondrial genes. Cold Spring Harbor Laboratory, Cold Spring Harbor, 137-141.

[28] Hauswirth, W.W. and Laipis, P.J. (1985) Transmission genetics of mammalian mitochondria: A molecular model and experimental evidence. In Quagliariello, E., Slater, E.C., Palmieri, F., Saccone, C. and Kroon, A.M., Eds., Achievement and perspectives of mitochondrial research. Vol. 2: Biogenesis, Elsevier Scientific Publishers, Amsterdam, 49-59.

[29] Ankel-Simons, F. and Cummins, J.M. (1996) Misconceptions about mitochondria and mammalian fertilization: implications for theories on human evolution. Proceedings of the National Academy of Sciences, USA, 93(4), 13859-13863.

[30] Sutovsky, P., Moreno, R.D., Ramalho-Santos, J., et al. (2000) Ubiquitinated sperm mitochondria, selective proteolysis and the regulation of mitochondrial inheritance in mammalian embryo. Biology of Reproduction, 63(2), 582-590.

[31] Gyllensten, U., Wharton, D., Josefsson, A. et al. (1991) Paternal inheritance of mitochondrial DNA in mice. $\mathrm{Na}$ ture, 352(6332), 255-257.

[32] Shibata, H., Hayashi, J.-I., Takahama, S., et al. (1998) Maternal inheritance of mouse mtDNA in interspecific hybrids: Segregation of the leaked paternal mtDNA followed by the prevention of subsequent paternal leakage. Genetics, 148(2), 851-857.

[33] Thyagarajan, B., Padua, R.A. and Campbell, C. (1996) Mammalian mitochondria possess homologous DNA recombination activity. Journal of Biological Chemistry, 271(44), 27536-27543.

[34] Lakshmipathy, U. and Campbell, C. (1999) Double strand break rejoining by mammalian mitochondrial extracts. Nucleic Acids Research, 27(4), 1198-1204.

[35] Lakshmipathy, U. and Campbell, C. (1999) The human DNA ligases III gene encodes nuclear and mitochondrial proteins. Molecular and Cellular Biology, 19(5), 38693876.

[36] Zhao, X., Li, N., Guo, W., et al. (2004) Further evidence for paternal inheritance of mitochondrial DNA in the sheep (Ovis aries). Heredity, 93(4), 399-403.

[37] Oppenheimer, S. (2003) Out of Eden. The peopling of the world. Constable and Robinson, London.

[38] Ashcroft, R. (2006) Race in medicine: From probability to categorical practice. In: Ellison, G.T.H. and Goodman, A.H., Eds., The nature of difference: Science, society and human biology. CRC press, Boca Raton, 135-153.

[39] Wilson, J.A.P. (2008) A new perspective on later migra- 
tion(s). The possible recent origin of some native American halotypes. Critique of Anthropology, 28(3), 267-278.

[40] Hammer, M.F., Karafet, T., Rasanayagam, A., et al. (1998) Out of Africa and back again: Nested cladistic analysis of human Y chromosome variation. Molecular Biology and Evolution, 15(4), 427-441.

[41] Underhill, P.A., Shen, P., Lin, A.A., et al. (2000) Y chromosome sequence variation and history of human population. Nature Genetics, 26(3), 358-361.

[42] Ke, Y., Su, B., Song, X., et al. (2001) African origin of modern humans in East Asia: A tale of 12,000 Y chromosomes. Science, 292(5519), 1151-1153.

[43] Balter, M. (2001) Anthropologists duel over modern human origins. Science, 291(5509), 1728-1729.

[44] Harris, E. and Hey, J. (1999) X-chromosome evidence for ancient human histories. Proceedings of the National Academy of Sciences, USA, 96(6), 3320-3324.

[45] Kaessmann, H., Heissig, F., von Haeseler, A., et al. (1999) DNA sequence variation in non-coding region of low recombination on the human X-chromosome. Nature Genetics, 22(1), 78-81.

[46] Harding, R.M., Fullerton, S.M., Griffiths, R.C., et al. (1997) Archaic African and Asian lineage in the genetic ancestry of modern humans. American Journal of Human Genetics, 60(4), 772-789.

[47] Zhao, Z., Jin, L., Fu, Y.-X., et al. (2000) World wide DNA sequence variation in a 10 -kilobase noncoding region on human chromosome 22. Proceedings of the $\mathrm{Na}$ tional Academy of Sciences, USA, 97(21), 11354-11358.

[48] Zhu, R.X., Potts, R., Xie, F., et al. (2004) New evidence on the earliest human presence at high northern latitudes in northeast Asia. Nature, 430(6999), 559-566.

[49] Dennell, R. and Roebroeks, W. (2005) An Asian perspective on early human dispersal from Africa. Nature, 438(7071), 1099-1104.

[50] Shen, G., Gao, X., Gao, B., et al. (2009) Age of Zoukoudian Homo erectus determined with ${ }^{26} \mathrm{Al} /{ }^{10} \mathrm{~B}$ burial dating. Nature, 458(7235), 198-200.

[51] Zhang, F., Su, B., Zhang, Y.-P., et al. (2007) Genetic studies of human diversity in East Asia. Philosophical Transactions of Royal Society B, 362(1482), 987-995.

[52] Naora, H. (2007) Morphological variation and sexual behaviour in the human past. II. The origin of East Asians and their sexual behaviour. Dokkyo Journal of Medical Sciences, 34(2), 141-151. 